\title{
Factors Affecting Choosing Peritoneal Dialysis Modality among Hemodialysis Patients in Single Center Study, Taif region, KSA
}

\author{
Faisal Alhomayani ${ }^{1}$, Mohammed Alsuwat ${ }^{* 2}$, Abdulhameed Sarriyah ${ }^{2}$, Hamoud Alotaibi ${ }^{2}$, \\ Rakan Almnjwami ${ }^{2}$, Hazem Althobaiti ${ }^{2}$, Abdullah Alsharif ${ }^{2}$ \\ ${ }^{1}$ Assistant Professor of internal medicine, College of Medicine, Taif University, Saudi Arabia \\ ${ }^{2}$ Medical Student, Taif University, Taif city, Saudi Arabia \\ *Corresponding author: Mohammed Alsuwat; Mohammed.alswut@hotmail.com
}

Received 19 June 2021;

Accepted 02 July 2021;

Published 05 July 2021

\begin{abstract}
Background: Renal replacement care of choices for end-stage renal disease (ESRD) patients include chronic dialysis either hemodialysis or peritoneal dialysis and kidney transplantation, the vast majority of patients use hemodialysis (HD) rather than peritoneal dialysis (PD). $\underline{\text { Methods: }}$ This is a single center cross sectional observational study in the King Abdul-Aziz Specialist Hospital, Taif, Saudi Arabia. The study was conducted from 20 October 2020 to 20 July 2021. The participants 135 patients, A survey was prepared by specialized authors, and selfanswered by hemodialysis patients after informed consent was approved by the participants to complete the survey. Statistical analysis was conducted using SPSS version 21. Result: Factors affecting choosing Peritoneal Dialysis modality among Hemodialysis patients in a single center among Saudi population were analyzed in the total number of cases 135 including $52 \%$ are males, $47.9 \%$ are females, presence of chronic diseases among our cases Hypertension, followed by Diabetes were the most important causes for the etiology of chronic kidney disease in $(51 \%, 33.3 \%)$, peritoneal dialysis was discussed with the majority of cases $(59.4 \%)$, The higher percentage of our participants deny any mental illness, eye disease, hernia or abdominal surgery or ischemic bowel disease.if PD modality was discussed with them and correlated with reasons for not picking PD, this was statistically significant proved by Pearson Chi square test with Confidence interval $95 \%$, $\mathrm{P}$ value $<0.05$. Conclusion: This study indicates that the cardinal patients' characteristics of young age, single, being ambulant, if PD was discussed with the patient are among the factors influencing choosing peritoneal dialysis among haemodialysis patients.
\end{abstract}

Keywords: Peritoneal Dialysis(PD), Hemodialysis (HD), Kidney Transplantation, Renal Replacement Therapy

\section{Introduction}

Renal replacement care of choices for end-stage renal disease (ESRD) patients include chronic dialysis either hemodialysis or peritoneal dialysis and kidney transplantation, the vast majority of patients use hemodialysis (HD) rather than peritoneal dialysis (PD). The prevalence of ESRD in combination with the cost of long-term dialysis treatment has resulted in increased interest in the analysis and understanding of factors which determine ${ }^{[1]}$. The eighty eight percentage of patients starting chronic dialysis, and who receive details about modalities for renal replacement therapy is unknown ${ }^{[2]}$. Deciding which of these methods is better suited to a specific patient depends on his / her residual renal function and providing the patient with adequate education on the modalities available to him / her ${ }^{[3]}$. Patient perceptions and results may be greatly influenced by the circumstances of dialysis initiation and the choices about initial modality and access. Lower survival and higher morbidity are associated with a lack of patient preparedness and an immediate start of dialysis ${ }^{[4,5]}$. The probability of patients choosing PD treatment is much higher if they have obtained details about alternatives for the modality of dialysis before RRT begins. To our knowledge, however, no studies investigated why patients with whom PD was addressed fail to seek PD treatment ${ }^{[2]}$. The cross-sectional study in 11 August 2020 about PD use, availability, accessibility, affordability, delivery and reporting of quality outcome measures in 160 countries reveal the median in 30 countries, particularly in Africa and other low-income countries PD was not available, and 38.1 per million of population use of PD. PD was the initial dialysis modality in $69 \%$ of countries for $\leq 10 \%$ of patients with newly diagnosed kidney failure. The study also reveal that the reporting and quality outcome monitoring of PD were variable and most countries did not measure patient-reported PD outcomes ${ }^{[6]}$. The Peritoneal dialysis (PD) has been suggested 
as an effective and safe dialysis modality in patients with acute kidney injury (AKI), provides the following advantages over hemodialysis (HD): there is no need for heparin therapy, no need for vascular access, vascularity of the patient remains intact, residual kidney function is preserved, hemodynamic and metabolic stability is preserved, blood pressure is monitored more closely, and complications due to regular blood transfusion such as viral hepatitis are minimal, improve quality of life, and Lower costs ${ }^{[7-9]}$. In addition to previous benefits of using PD there are many small studies suggested that PD may reduce the mortality compared with HD In 2017 the study was included 2032 patients all patient developed ESRD, the about comparison patients survival between Hemodialysis and Peritoneal dialysis, the study was exclude one third of all incident patients seems to be ineligible for PD, among patients younger than 65 years Peritoneal Dialysis was associated with lower risk for death, the study show regardless of age both modalities have similar survival rate. The study reveal that the future study in comparison of modalities should be restricted to patients who are eligible for both $\mathrm{HD}$ and $\mathrm{PD}$ to reflect the outcomes of choosing between them ${ }^{[10]}$. Patients also require frequent reassessments to decide whether they want to maintain the current modality or need to transition to another modality ${ }^{[11]}$. However, the evidence show that PD leads to greater protection of RRF than HD in the initial years of treatment ${ }^{[12,13]}$. The number of patient with end stage renal disease (ESRD) using PD modality is less than $8 \%$ of total ESRD patients; by the end of 2019, there were 19522 patients on hemodialysis, 1546 patients on peritoneal dialysis, and 14,762 with functioning kidney grafts ${ }^{[14]}$. Increased awareness of patients with advanced kidney impairment or hemodialysis patients regarding PD and its benefits may contribute to increase picking this choice of modality, Reviewed study was done in June 2019 about shared decision making increase living kidney transplantation and peritoneal dialysis, the study was conducted in 2017 to 310 patients who receive long term renal replacement therapy and 220 of them completed Shared Decision Making about their choice of RRT and 66 of them received Peritoneal dialysis and 67 patients entered the evaluation of living related Kidney Transplantation program and 18 patients received operation for living KT. The study show that after implementation of Shared decision making in 2017 the number of living kidney transplantation and peritoneal dialysis was drastically increase ${ }^{[15]}$. The inadequate education on the dialysis modality options with patients with advanced chronic kidney disease leads to difficult to choose of modality, and also there are not many studies talking about it especially in our country. Once we understand the important education of patient about dialysis modality before started, lead to increase public background about this important issue. The currently study aims to study the degree of awareness about PD modality on patients undergoing hemodialysis in Taif, Saudi Arabia and to identify if there are factors that limit using this type of renal replacement therapy.

\section{Methods}

\section{Study design}

This is a single center cross sectional observational study in the King Abdul-Aziz Specialist Hospital, Taif, Saudi Arabia. The study was conducted from 20 October 2020 to 20 July 2021.

\section{Sampling size and participants}

All the following participants 135 patients met the following Inclusion criteria:
1. Over the age of 18.

2. Patient willing to participate in the study.

3. Patients whose native language is not Arabic will be excluded from the study as

This may influence the results of study given that the survey will be in Arabic language.

Exclusion criteria for participants with known Mental illnesses, acute kidney injury with emergent dialysis, eye disease, patients not welling for PD, presence of hernia, diverticulitis, abdominal surgery prior to hemodialysis, in addition to non ambulant patients.

\section{The Questionnaire}

A survey was prepared by specialized authors, and self-answered by hemodialysis patients after informed consent was approved by the participants to complete the survey. All participants had the right to withdraw from the study at any time if they wish to do so. We retrospectively demonstrated the demographic characteristics, personal disease loads, and awareness of the patients regarding Peritoneal dialysis was best shown in answering questions about if he had predialysis nephrology care or not, if PD modality discussed with him/her or not, used PD before or not, and reason to not pick $\mathrm{PD}$, duration he had on hemodialysis in a closed ended questions Chronic diseases comorbidity were questioned in three questions.

\section{Statistical Analysis}

Means and standard deviations for continuous data and frequencies and percentages for categorical data are elaborated to present patient characteristics. Univariate analyses, and univariate logistic regression analysis or chi-square tests for categorical variables, were utilized to study correlations between factors and dialysis modality. For dichotomized outcomes in these questions (if he had predialysis nephrology care, if he used PD before, if PD modality was discussed with him before) the responses were counted as (Yes, No) as a nominal variable. Predictors or risk factors for choosing PD were calculated using univariate logistic regression analysis. Statistical analysis was conducted using SPSS version 21 (SPSS Inc., Armonk, NY: IBM Corp, USA) and a 2-sided test with $\mathrm{p}<0.05$ was set as the cut-off value for statistical significance at 95\% confidence interval.

\section{Results}

Factors affecting choosing Peritoneal Dialysis modality among Hemodialysis patients in a single center among Saudi population were analyzed in the total number of cases 135. Descriptive demographic statistics were presented in (Table 1) showing age mean and SD (50.42 \pm 15.37$), 52 \%$ are males, $47.9 \%$ are females, $71.4 \%$ of the participants are married, socioeconomic state, educational level, occupation, ambulant state, living alone. Descriptive Analysis of the questionnaire questions regarding etiology of chronic kidney disease, total duration being on Hemodialysis, Predialysis nephrology care, all questions concerned with Peritoneal dialysis if used before, discussed with the patient, reasons of not picking PD are presented in (Table 2). Univariate analysis using Chi-square test was used to find out correlation between different variables, logistic regression analysis was done to identify factors affecting the choice of peritoneal dialysis. 
Table 1: Demographic descriptive characteristics of the participants and Univariate analysis of the factors affecting the choice of PD among hemodialysis patients

\begin{tabular}{|c|c|c|c|c|c|}
\hline \multicolumn{2}{|l|}{ Variable } & $\mathbf{N}$ & $(\%)$ & Chi-square & $P$ value \\
\hline \multirow{2}{*}{$\begin{array}{l}\text { Age } \\
\text { Range (16-90) Mean } \pm \text { SD }(50.42 \\
\pm 15.37)\end{array}$} & Less than 40 years & 35 & $25.2 \%$ & \multirow[b]{2}{*}{0.344} & \multirow[b]{2}{*}{0.000} \\
\hline & More tha40 years & 104 & $74.8 \%$ & & \\
\hline \multirow[b]{2}{*}{ Gender } & Males & 73 & $52.1 \%$ & \multirow[t]{2}{*}{0.196} & \multirow[t]{2}{*}{0.767} \\
\hline & Females & 67 & $47.9 \%$ & & \\
\hline \multirow{4}{*}{ Marital status } & Single & 30 & $21.4 \%$ & \multirow{4}{*}{17.895} & \multirow{4}{*}{0.000} \\
\hline & Married & 100 & $71.4 \%$ & & \\
\hline & Widow & 7 & $5.0 \%$ & & \\
\hline & Divorced & 3 & $2.1 \%$ & & \\
\hline \multirow{3}{*}{ Socioeconomic } & Less than $5000 \mathrm{SR}$ & 52 & $48.1 \%$ & \multirow{3}{*}{0.677} & \multirow{3}{*}{0.713} \\
\hline & 5000-10000 SR & 50 & $46.3 \%$ & & \\
\hline & More than 10000 SR & 6 & $5.6 \%$ & & \\
\hline \multirow{4}{*}{ Educational level } & Below High School & 77 & $55.4 \%$ & \multirow{4}{*}{3.372} & \multirow{4}{*}{0.338} \\
\hline & High School & 35 & $25.2 \%$ & & \\
\hline & Bachelor's & 26 & $18.7 \%$ & & \\
\hline & Masters & 1 & $0.7 \%$ & & \\
\hline \multirow[t]{2}{*}{ Occupation } & Yes & 38 & $27.1 \%$ & \multirow[t]{2}{*}{0.491} & \multirow[t]{2}{*}{0.590} \\
\hline & No & 102 & $72.9 \%$ & & \\
\hline \multirow[t]{3}{*}{ Ambulant } & Mobile without support & 102 & $76.7 \%$ & \multirow{3}{*}{12.86} & \multirow{3}{*}{0.002} \\
\hline & Use Occupational aids & 27 & $20.3 \%$ & & \\
\hline & Bedridden & 4 & $3.0 \%$ & & \\
\hline \multirow[t]{2}{*}{ Living Alone } & Yes & 23 & $16.4 \%$ & \multirow[t]{2}{*}{0.001} & \multirow[t]{2}{*}{1.000} \\
\hline & No & 117 & $83.6 \%$ & & \\
\hline
\end{tabular}

Table (1) shows the descriptive demographic characteristics of our participants: Age, gender, marital status, educational level, socioeconomic level, occupation, ambulant status, and living alone. Univariate analysis was done using Chi-square test of independence and shows that factors affecting the choice of Peritoneal Dialysis modality among hemodialysis patients are age less than 40 years $(p=0.000)$, being single ( $p=0.000)$, being ambulant mobile without support $(p=0.002) . P$ is considered statistically significant if $<0.05$ two tailed test.

Table 2: Descriptive and Univariate analysis of the Questionnaire assessing the factors influencing the choice of Peritoneal dialysis among our cases

\begin{tabular}{|c|c|c|c|c|c|}
\hline \multicolumn{2}{|l|}{ Variable } & $\mathbf{N}$ & $(\%)$ & Chi-square & P value \\
\hline \multirow{7}{*}{ Etiology of Chronic kidney disease } & $\mathrm{DM}$ & 49 & $33.3 \%$ & \multirow{7}{*}{7.81} & \multirow{7}{*}{0.252} \\
\hline & HTN & 75 & $51 \%$ & & \\
\hline & Congenital causes & 3 & $2 \%$ & & \\
\hline & Obstructive Uropathy & 2 & $1.4 \%$ & & \\
\hline & Glomerulonephritis & 4 & $2.7 \%$ & & \\
\hline & Polycystic Kidney disease & 2 & $1.4 \%$ & & \\
\hline & Unknown & 4 & $2.7 \%$ & & \\
\hline \multirow{3}{*}{$\begin{array}{l}\text { How long have you been doing } \\
\text { Hemodialysis? }\end{array}$} & Less than 5 years & 61 & $43.6 \%$ & \multirow[t]{3}{*}{-0.248} & \multirow[t]{3}{*}{0.010} \\
\hline & $5-10$ years & 43 & $30.7 \%$ & & \\
\hline & More than 10 years & 36 & $25.7 \%$ & & \\
\hline \multirow[t]{2}{*}{ Had Predialysis Nephrology Care with him } & Yes & 92 & $65.7 \%$ & \multirow[t]{2}{*}{0.509} & \multirow[t]{2}{*}{0.545} \\
\hline & No & 48 & $34.3 \%$ & & \\
\hline \multirow{2}{*}{$\begin{array}{l}\text { If Peritoneal Dialysis discussed with the } \\
\text { Patient }\end{array}$} & Yes & 82 & $59.4 \%$ & \multirow[t]{2}{*}{4.89} & \multirow[t]{2}{*}{0.030} \\
\hline & No & 56 & $40.6 \%$ & & \\
\hline \multirow[t]{2}{*}{ Did he used Peritoneal Dialysis before? } & Yes & 12 & $9 \%$ & \multirow[t]{2}{*}{134.0} & \multirow[t]{2}{*}{0.000} \\
\hline & No & 122 & $91 \%$ & & \\
\hline \multirow{2}{*}{$\begin{array}{l}\text { What are the reasons of not picking } \\
\text { Peritoneal Dialysis? }\end{array}$} & PD not fit for me contraindications & 12 & $9 \%$ & \multirow[t]{2}{*}{0.193} & \multirow[t]{2}{*}{0.000} \\
\hline & PD not suitable for Me & 122 & $91 \%$ & & \\
\hline \multirow[t]{2}{*}{ Presence of Mental illness or Eye disease } & Yes & 68 & $48.6 \%$ & \multirow[t]{2}{*}{0.990} & \multirow[t]{2}{*}{0.376} \\
\hline & No & 72 & $51.4 \%$ & & \\
\hline \multirow[t]{2}{*}{ Abdominal Surgery prior to HD start } & Yes & 40 & $28.6 \%$ & \multirow[t]{2}{*}{2.601} & \multirow[t]{2}{*}{0.178} \\
\hline & No & 100 & $71.4 \%$ & & \\
\hline \multirow[t]{2}{*}{ Presence of Hernia prior to HD } & Yes & 15 & $10.7 \%$ & \multirow[t]{2}{*}{1.661} & \multirow[t]{2}{*}{0.360} \\
\hline & No & 125 & $89.3 \%$ & & \\
\hline \multirow{2}{*}{$\begin{array}{l}\text { Presence of diverticulitis// IBD/ ischemic } \\
\text { bowel disease }\end{array}$} & Yes & 26 & $18.6 \%$ & \multirow[t]{2}{*}{1.636} & \multirow[t]{2}{*}{0.247} \\
\hline & No & 114 & $81.4 \%$ & & \\
\hline
\end{tabular}


Table (2) Describe variables related to dialysis process and presence of chronic diseases among our cases. Hypertension, followed by Diabetes were the most important causes for the etiology of chronic kidney disease in (51\%, 33.3\%), 43.6\% of our participants have been less than 5 years on hemodialysis, $65.7 \%$ of them admit having predialysis nephrology care with them, peritoneal dialysis was discussed with the majority of cases (59.4\%), however it was actually used before in (12) 9\% of them and the majority of them $91 \%$ informed that PD was not suitable for them, while 9\% have contraindications for PD. The higher percentage of our participants deny any mental illness, eye disease, hernia or abdominal surgery or ischemic bowel disease.

Table 3: Crosstabulation between previous use of Peritoneal Dialysis in different aetiologias of chronic kidney diseases

\begin{tabular}{|l|l|l|l|}
\hline $\begin{array}{l}\text { Aetiology of chronic kidney disease } \\
\text { * Did he used Peritoneal Dialysis before Crosstabulation }\end{array}$ & Total \\
\hline Aetiology of chronic kidney disease & Did he used PD before? & 46 \\
\cline { 2 - 4 } & Yes & No & 72 \\
\hline DM & 5 & 41 & 3 \\
\hline HTN & 5 & 67 & 2 \\
\hline Congenital causes & 1 & 2 & 4 \\
\hline Obstructive uropathy & 0 & 2 & 2 \\
\hline Glomerulonephritis & 0 & 4 & 4 \\
\hline Polycystic kidney disease & 1 & 1 & $\mathbf{1 3 3}$ \\
\hline Unknown & 0 & 4 & $\mathbf{1 2 1}$ \\
\hline Total & $\mathbf{1 2}$ & \\
\hline
\end{tabular}

Table (3): This Crosstabulation shows that the higher aetiology of chronic kidney diseases is hypertension ( 72 out of 133 cases), followed by Diabetes (46 out of 133 cases), followed by other causes.

Factors affecting the choice of PD if Peritoneal dialysis has been discussed with the patient before $(\mathrm{p}=0.030)$, whether the patient used the PD before $(\mathrm{p}=0.00)$, reasons of not picking $\mathrm{PD}$ as a first choice either because it is contraindicated or not suitable $(\mathrm{p}=0.00)$ all these are statistically significant correlated with the choice of $\mathrm{PD}$, by using Chi-square test as $\mathrm{p}<0.05$ at $95 \%$ CI two tailed test.

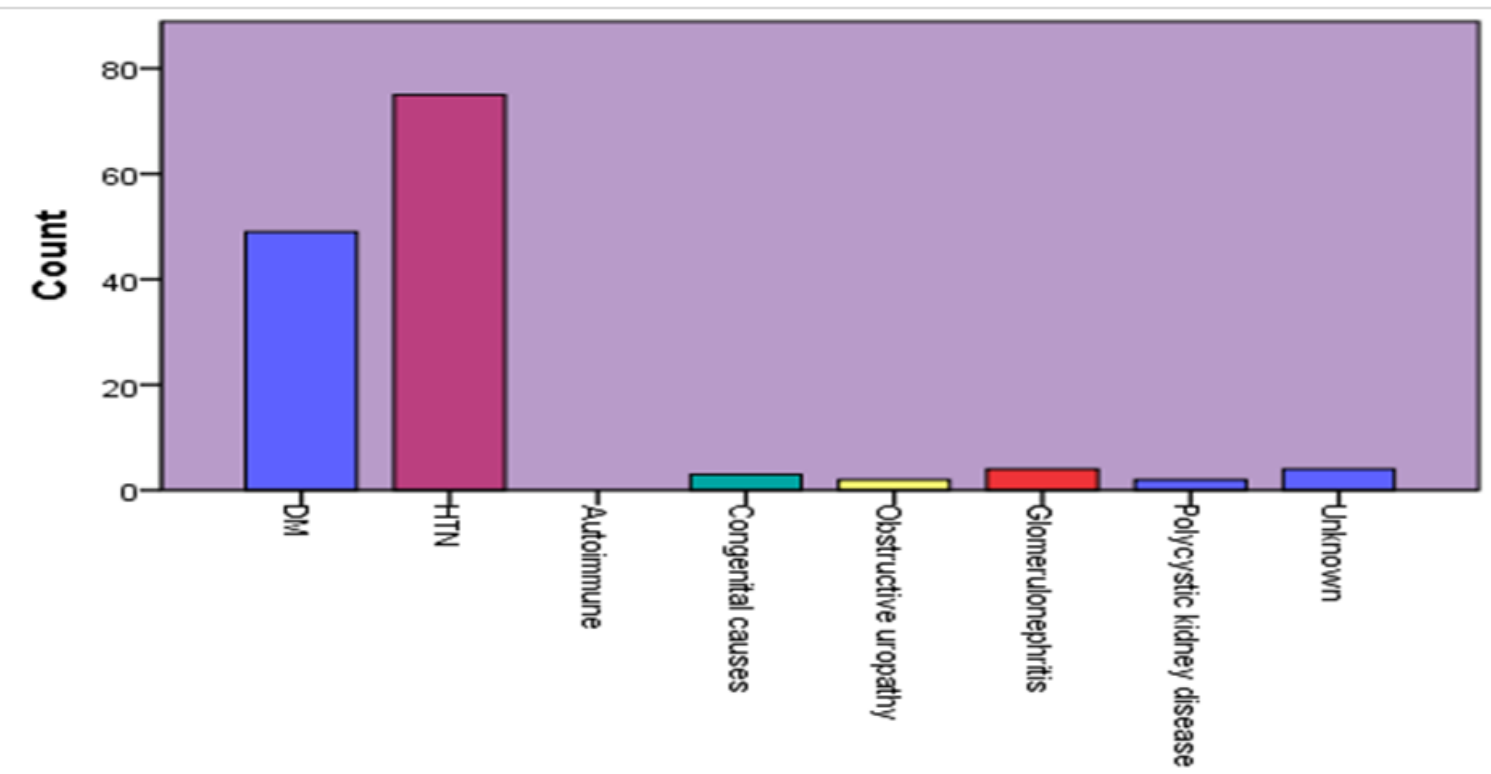

Etiology of chronic kidney disease

Fig (1): Different aetiologies of chronic kidney disease presents Hypertension as the top cause for chronic kidney disease in $54 \%$ of total cases, DM as $35.3 \%$, Glomerulonephritis as $2.9 \%$, unknown causes as $2.9 \%$, congenital causes as $2.2 \%$, Obstructive uropathy and Polycystic kidney disease as each of them as $1.4 \%$.

Factors affecting the Choice of Peritoneal Dialysis among Haemodialysis patients

Factors influencing the choice of PD were age less than 40 years, single marital state, being ambulant, if PD modality was discussed with him and correlated with reasons for not picking PD, this was statistically significant proved by Pearson Chi square test with Confidence interval $95 \%, \mathrm{P}$ value $<0.05$ two tailed test. Gender, socioeconomic level, educational level, aetiology of chronic kidney disease, presence of any chronic diseases is not correlated significantly with the use of PD.

\section{Discussion}

There is growing evidence that from the renal replacement modality selection that is offered for chronic kidney diseases patient's all-over the world, peritoneal dialysis is underutilized. This is the case in kingdom of Saudi Arabia where only 9\% of dialysis patients are using PD and that percentage remains the same over the years ${ }^{[16]}$. Surprisingly, in our study we came with the same results that only 9\% did used PD previously among haemodialysis patients. This is quite similar with the results in the United States, where $87.3 \%$ of the patients with end-stage renal 
disease (ESRD) in need of dialysis are on haemodialysis (HD) and $12.7 \%$ are utilizing peritoneal dialysis $(\mathrm{PD})^{[17]}$. On the other hand, in a survey-based questionnaire in Canada identifying the present dialysis modality percentages, Canadian nephrologists reported that $34 \% \mathrm{PD}$ versus $66 \%$ are using $\mathrm{HD}{ }^{[18]}$. Which is the case in countries like India where in a single centre study they found that only $6 \%$ of end-stage renal disease patients undergoing dialysis are on PD ${ }^{[19]}$. Factors affecting decision making in dialysis modality and barriers to choose PD in our Saudi participants were analysed.

Our results showed that despite the higher proportion of our participants admitted predialysis nephrology care with them, and PD modality was discussed with him/her before, yet lower proportion goes with this choice either due to contraindication or not suitable for them. In Taiwan, according to the guidelines of pre-ESRD care program, educational program was restricted for only late cases of chronic kidney disease ${ }^{[20]}$, CKD patients who received predialysis education were found to choose the dialysis modality based on past experience of peers, or get opinions from families or friends, more than the opinion of the medical staff ${ }^{[21]}$. Presence of educational programs offered to the patients in predialysis clinics in a timely manner will definitely expand the referral and usage of PD and its shortage is most probably among the causes of underutilization of PD in Saudi Arabia ${ }^{[16]}$.

A clear evidence indicates that being ambulant without support was shown to be a crucial factor in choosing PD in our study (OR= 2.88 CI (1.339- 6.209) Patients with independent ADL were associated with a higher percentage of PD therapy than those who needs support because of the flexibility and the comfort provided by this dialysis modality, this was reported in a study in Taiwan, they found that the ADL rating was an independent factor influencing the selection of dialysis ${ }^{[21]}$.

Young age is a statistically significant variable which is highly correlated with the choice of PD with OR=10.2 CI (2.53341.74), this goes in agreement with Chiang and his colleagues in his study who recognised young age as a statistically significant factor (OR 3.309 CI (1.683-6.507) with $\mathrm{p}<0.001^{[20]}$. Researchers from Uk have correlated younger age groups with choosing PD ${ }^{[22]}$, Some researchers emphasis on the level of education as one of the factors, however our results did not point out any statistical significance with level of education. Our results and Chiang reported no statistically significant correlation of gender in choosing the dialysis modality ${ }^{[20]}$. Patients preferring PD as an optimal dialysis modality show a mean of lower score of chronic disease co-morbidity ${ }^{[22]}$, However, our results showed no statistically significant correlation between comorbidity and choosing PD.

In Bangladesh, researchers pointed out that cost of supplies, lack of trained medical staff, patients lack of good hygiene or caregiver support were the top barriers to PD expansion from nephrologists' perspectives ${ }^{[23]}$.

In a Saudi study, Dahlan and colleagues questioned about the mode of dialysis nephrologists would choose if they needed for themselves, $(74 \%)$ chose PD.

\section{Recommendations}

The top 3 most common recommendations given by nephrologists to expand the use of PD in Saudi Arabia were:

1. Predialysis Clinic for chronic kidney disease patients to provide adequate education.

2. Prompt referral.

3. Escalate nephrologists' motivation with continuous medical education (CME) ${ }^{[16]}$.

\section{Limitations}

Our study has some limitations, mainly it is a single center crosssectional study, which makes it difficult to generalise the results to other dialysis centres. We aimed to identify the factors affecting the choice of PD among hemodialysis patients. The choice is affected by some other variables like concerns about complications, support of the family members, living conditions, quality of life after starting dialysis modality, nephrologist's motivation, and the cost of the dialysis whether the payment is through insurance or by himself. All these confounders were not assessed. This study has a strong implication where it highlighted the main crucial factors shaping the patient's awareness perspectives in his choice which is vital to be addressed to improve PD implementation.

\section{Conclusion}

This study indicates that the cardinal patients' characteristics and factors influencing choosing peritoneal dialysis among haemodialysis patients were age less than 40 years, being single marital state, being ambulant, if PD modality was discussed with him and correlated with reasons for not picking PD, Gender, socioeconomic level, educational level, aetiology of chronic kidney disease, presence of any chronic diseases is not correlated significantly with the use of PD. Future large randomized controlled studies are highly recommended to explore all possible reasons behind choosing PD. We recommend increase public awareness, multidisciplinary educational programs to promote $\mathrm{PD}$ as an efficient dialysis modality.

\section{Acknowledgements}

The authors express their gratitude to the director and clerks of the studied hospital who facilitated the administrative aspects related to this study.

\section{Ethics approval}

Institutional research ethics board approval was acquired before conducting any study-related procedures. A statement was included at the beginning of the questionnaire clarifying that the participation in this study is voluntary and that collected data will be anonymous and will only be used for this study.

\section{Conflicts of Interest}

The authors have no conflicts of interest to declare.

\section{Source of Funding}

This study did not receive any specific grant from funding agencies in the public, commercial, or not-for-profit sectors.

\section{References}

[1] Saran R, Robinson B, Abbott KC, Agodoa LYC, Albertus P, Ayanian J, et al. US Renal Data System 2016 Annual Data Report: Epidemiology of Kidney Disease in the United States. Am J Kidney Dis. 2017 Mar;69(3):A7-8. 
[2] Kutner NG. Patient Awareness and Initiation of Peritoneal Dialysis. Arch Intern Med. 2011 Jan;171(2):119.

[3] Ghafari A, Sepehrvand N, Hatami S, Ahmadnejad E, Ayubian B, Maghsudi R, et al. Effect of an educational program on awareness about peritoneal dialysis among patients on hemodialysis. Saudi J Kidney Dis Transpl. $2010 \mathrm{Jul} ; 21(4): 636-40$.

[4] Tennankore KK, Soroka SD, Kiberd BA. The impact of an "acute dialysis start" on the mortality attributed to the use of central venous catheters: a retrospective cohort study. BMC Nephrol. 2012 Dec;13(1):72.

[5] Hasegawa T, Bragg-Gresham JL, Yamazaki S, Fukuhara S, Akizawa T, Kleophas W, et al. Greater First-Year Survival on Hemodialysis in Facilities in Which Patients Are Provided Earlier and More Frequent Pre-nephrology Visits. Clin J Am Soc Nephrol. 2009 Mar;4(3):595-602.

[6] Htay H, Bello AK, Levin A, Lunney M, Osman MA, Ye F, et al. Hemodialysis Use and Practice Patterns: An International Survey Study. Am J Kidney Dis. 2020 Aug;

[7] Blake PG. Peritoneal Dialysis in Asia: An External Perspective. Perit Dial Int J Int Soc Perit Dial. 2002 Mar;22(2):258-64.

[8] Dimkovic N, Oreopoulos DG. Chronic Peritoneal Dialysis in the Elderly. Semin Dial. 2002 Mar;15(2):947.

[9] Heaf JG, Løkkegaard H, Madsen M. Initial survival advantage of peritoneal dialysis relative to haemodialysis. Nephrol Dial Transplant. 2002 Jan;17(1):112-7.

[10] Wong B, Ravani P, Oliver MJ, Holroyd-Leduc J, Venturato L, Garg AX, et al. Comparison of Patient Survival Between Hemodialysis and Peritoneal Dialysis Among Patients Eligible for Both Modalities. Am J Kidney Dis. 2018 Mar;71(3):344-51.

[11] Guo A, Mujais S. Patient and technique survival on peritoneal dialysis in the United States: Evaluation in large incident cohorts. Kidney Int. 2003 Dec;64(88):S312.

[12] Jansen MAM, Hart AAM, Korevaar JC, Dekker FW, Boeschoten EW, Krediet RT. Predictors of the rate of decline of residual renal function in incident dialysis patients. Kidney Int. 2002 Sep;62(3):1046-53.
[13] Ueda A, Nagai K, Hirayama A, Saito C, Yamagata K. Peritoneal Dialysis Preserves Residual Renal Function and Reduces Oxidative Stress During the Initial Period of Dialysis Therapy. Adv Perit Dial. 2017 Jan;33(2017):1821.

[14] Saudi Center for Organ Transplantation. Annual Report for Organ Transplantation in the Kingdom of Saudi Arabia. 2017;

[15] Lee C-T, Cheng C-Y, Yu T-M, Chung M-C, Hsiao C-C, Chen $\mathrm{C}-\mathrm{H}$, et al. Shared Decision Making Increases Living Kidney Transplantation and Peritoneal Dialysis. Transplant Proc. 2019 Jun;51(5):1321-4.

[16] Dahlan R, Qureshi M, Akeely F, Al Sayyari AA. Barriers to Peritoneal Dialysis in Saudi Arabia: Nephrologists' Perspectives. Perit Dial Int. 2016 Sep;36(5):564-6.

[17] Mendelssohn DC, Mullaney SR, Jung B, Blake PG, Mehta RL. What do American nephrologists think about dialysis modality selection? Am J Kidney Dis. 2001 Jan;37(1):22-9.

[18] Jung B, Blake PG, Mehta RL, Mendelssohn DC. Attitudes of Canadian nephrologists toward dialysis modality selection. Perit Dial Int. 1999 May;19(3):2638.

[19] Mahajan S, Tiwari SC, Kalra V, Bhowmik DM, Agarwal SK. Factors affecting the use of peritoneal dialysis among the ESRD population in India: a single-center study. Perit Dial Int. 2004 Nov;24(6):538-41.

[20] Chiang P-C, Hou J-J, Jong I-C, Hung P-H, Hsiao C-Y, Ma T-L, et al. Factors Associated with the Choice of Peritoneal Dialysis in Patients with End-Stage Renal Disease. Biomed Res Int. 2016;2016:5314719.

[21] Winterbottom AE, Bekker HL, Conner M, Mooney AF. Patient stories about their dialysis experience biases others' choices regardless of doctor's advice: an experimental study. Nephrol Dial Transplant. 2012 Jan;27(1):325-31.

[22] Chanouzas D, Ng KP, Fallouh B, Baharani J. What influences patient choice of treatment modality at the pre-dialysis stage? Nephrol Dial Transplant. 2012 Apr;27(4):1542-7.

[23] Savla D, Ahmed S, Yeates K, Matthew A, Anand S. Barriers to Increasing Use of Peritoneal Dialysis in Bangladesh: A Survey of Patients and Providers. Perit Dial Int J Int Soc Perit Dial. 2017 Mar;37(2):234-7. 